\title{
An Abstract of Empowering Poetry About Sustainability: The Rap Video Review
}

\author{
Mark Peterson
}

\begin{abstract}
Belk (2010, p. 288) notes how rap music and the hip-hop culture from which it emerged are the latest instantiation of coolness. In this regard, rap is an attitude of nonconformity that opposes the mainstream. Such opposition is congruent with life projects those in their late teens and early twenties are involved, such as breaking free of family and establishing one's independence and identity. In a similar way, sustainable business practices represents nonconformity to traditional forms of business that degraded the natural environment and ignored human issues with impunity. For example, outdoor-gear company Patagonia and its founder and CEO Yvon Chouinard reject such a traditional approach to business in their mission to improve the natural environment. Accordingly, rapping about sustainability allows convergence of rap's celebration of the nonconformist and the cool rebelliousness of sustainable business practices. Sustainability is one of the major themes of contemporary business practice. The following teaching innovation allows students to engage in creative experiential learning focused on writing poetry about a sustainability topic and then recording a three-minute rap video based on this poetry. The rap video project described in this paper offers students an opportunity to apply critical and creative thinking skills in the development of their artistic video and to later become teachers for their fellow students. Mastery of the sustainability topic is a result of this process evidenced by (1) deep engagement in the project, (2) reshaping ideas into the vernacular of an urban setting, and (3) presenting the finished product in a visual form that demonstrates not only competence but confidence in the students' point of view about the sustainability topic.
\end{abstract}

\footnotetext{
M. Peterson $(\square)$

University of Wyoming, Laramie, WY, USA

e-mail: markpete@uwyo.edu
} 